\title{
Impact of Grit on Organizational Turnover: Empirical Results of International vs. US Gen Z/Millennial Cusp: An Abstract
}

\author{
Michael Rodriguez, Stefanie Boyer, David Fleming, and Scott Cohen
}

\begin{abstract}
In today's global sales environment, managers are posed with the challenge, "How do we retain our top people to stay?" Employee turnover has been an ongoing and perhaps an increasing problem due to the new generation's inability to deal with adverse conditions in today's challenging, global environment. The current study's goal is to analyze the next generation of the workforce, Generation Z/Millennial cusp, and compare differences between international and US students. Born between the mid-1990s and 2000, Gen Z/Millennial potentially introduces a challenge consistent with the millennial generation, organizational turnover. Analyzing responses from 293 international and US students, the following research focuses on a conceptual model that includes two constructs, individual entrepreneurship orientation (IEO) and grit and how those constructs impact company loyalty. The results indicate that there is a negative relationship between IEO and loyalty and that grit positively moderates the relationship between IEO and loyalty. The multigroup analysis shows there was not a significant difference between the international and US student sample in any of the structural paths. However, the results show that the moderating effect of grit is significant for the international sample. In today's global economy, hiring managers need to evaluate both local and international talent according to their hiring needs. Managers can utilize the findings when considering the importance of grit and entrepreneurial orientation in long-term organizational business performance.
\end{abstract}

References Available Upon Request

M. Rodriguez $(\bowtie) \cdot S$. Cohen

Skema Business School, Raleigh, NC, USA

e-mail: michael.rodriguez@ skema.edu; scott.cohen@skema.edu

S. Boyer

Bryant University, Smithfield, RI, USA

e-mail: sboyer@ skema.edu

D. Fleming

Indiana State University, Terre Haute, IN, USA

e-mail: david.fleming@indstate.edu 